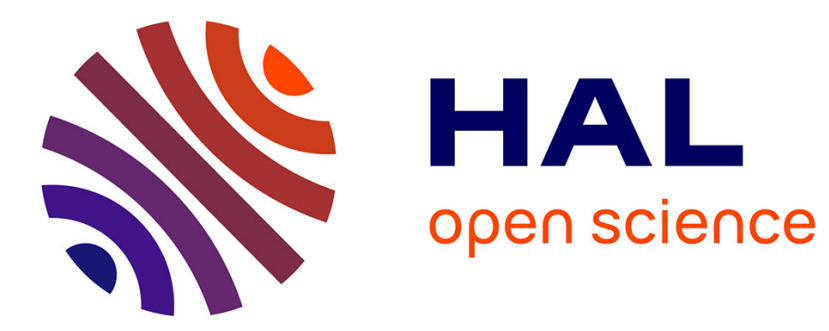

\title{
The three wives problem and Shapley value
}

Louis de Mesnard

\section{To cite this version:}

Louis de Mesnard. The three wives problem and Shapley value. Revue de Philosophie Economique / Review of Economic Philosophy, 2015, 2015 (2), pp.145-169. hal-01091714

\section{HAL Id: hal-01091714 https://hal.science/hal-01091714}

Submitted on 3 Dec 2021

HAL is a multi-disciplinary open access archive for the deposit and dissemination of scientific research documents, whether they are published or not. The documents may come from teaching and research institutions in France or abroad, or from public or private research centers.
L'archive ouverte pluridisciplinaire HAL, est destinée au dépôt et à la diffusion de documents scientifiques de niveau recherche, publiés ou non, émanant des établissements d'enseignement et de recherche français ou étrangers, des laboratoires publics ou privés. 


\title{
The three wives problem and Shapley value
}

\author{
Louis de Mesnard
}

Univ. Bourgogne Franche-Comté, CREGO (EA 7317), IAE Dijon ; 2 Bd

Gabriel, 21000 DIJON, FRANCE. E-mail: louis.de-mesnard@u-bourgogne.fr

\begin{abstract}
We examine the Talmudic three wives problem, which is a generalization of the Talmudic contested garment problem solved by Aumann and Maschler (1985) using coalitional procedure. This problem has many practical applications. In an attempt to unify all Talmudic methods, Guiasu (2010, 2011) asserts that it can be explained in terms of "run-to-the-bank", that is, of Shapley value in a "cumulative game". It can be challenged because the coalitional procedure yields the same result as the nucleolus, which corresponds to a "dual game". As Guiasu's solution is paradoxical (it has all the appearances of truth), my contribution consists in explaining the concepts, particularly truncation, that play a central role in the demonstration, and then analyzing in what way Guiasu's argument is misleading. After recalling what the Talmudic division problem is, how it is solved by Aumann and Maschler's coalitional procedure (i.e., the nucleolus or the Shapley value of the dual game), and how Guiasu solves it by the Shapley value of a cumulative game, I show that (i) Guiasu omitted to truncate the data (claims exceeding the value of the estate must be reduced to the available level of estate), while truncation is required in the context. (ii) He attributes the surplus (obtained after sharing out the estate) to all applicants equally: this contradicts the contested garment solution. (iii) This implies that the estate cannot exceed the greatest claim, which is obviously false. (iv) Guiasu's approach violates the axiom of continuity of payoffs. I conclude that Guiasu's attempt to explain the three wives problem in terms of "run-to-the-bank" is unsuccessful and actually contradicts the contested garment problem.

Résumé

Nous examinons un des problèmes talmudiques historiques, les trois épouses, une généralisation du problème talmudique du vêtement contesté, résolu par Aumann et Maschler (1985) en utilisant la procédure coalitionnelle. Ce problème a de nombreuses applications pratiques. Dans sa tentative pour unifier toutes les méthodes talmudiques, Guiasu (2010, 2011) dit qu'il peut être expliqué en termes de "ruée vers la banque", c.a.d. de valeur de Shapley dans un "jeu cumulatif". Cette approche doit être reconsidérée parce que la procédure coalitionnelle donne le même résultat que le nucléolus qui correspond à un "jeu dual". Comme la solution de
\end{abstract}


Guiasu est paradoxale (elle a toutes les apparences de la vérité), ma contribution est d'expliquer les concepts, principalement la troncation qui joue un rôle central dans la démonstration, puis d'analyser en quoi l'argument de Guiasu est inadapté. Après avoir rappelé ce qu'est le problème du partage selon le Talmud, comment il est résolu par la procédure coalitionnelle d'Aumann et Maschler (c.à.d. le nucléolus ou la valeur de Shapley du jeu dual) et comment Guiasu la résout par la valeur de Shapley d'un jeu cumulatif, on montre que: 1) Guiasu a omis de tronquer de données (les demandes qui dépassent la richesse doivent être réduites au niveau de la richesse disponible) alors que c'est nécessaire ici. 2) Il attribue l'excédent (obtenu après le partage de la richesse) à tous les candidats de manière égale: cela contredit la solution du vêtement contesté. 3) Ceci implique que la richesse ne peut pas dépasser la plus grande demande, ce qui est évidemment faux. 4) L'approche de Guiasu viole l'axiome de continuité des paiements. On conclut que la tentative de Guiasu de réunifier les méthodes de partage selon le Talmud par la valeur de Shapley est n'est pas couronnée de succès et est en fait contradictoire avec le vêtement contesté.

Keywords. Shapley value; contested garment; three wives; Talmudic division

Mots clés. Valeur de Shapley ; Vêtement Contesté ; Trois Epouses; partage selon le Talmud

JEL classification. D31, D63, D71, B1, B4

\section{Introduction}

Historically, there are two main methods of dividing a quantity of some commodity between two people: Aristotle's and the Talmud's. Applications of these methods of division are widespread, ranging from bankruptcy (how to allocate assets among creditors) to divorce (how to allocate the estate between two consorts) where there are contending claimants, via airport landing rights (Littlechild and Owen 1973) and the sovereign debt default problem (Fon 2012). ${ }^{1}$ Moulin (2003, p. 139) also cites joint-ventures and more generally the commons, the division of copyrights and other artistic rights, cost sharing, evaluation of the impact of each operator in environmental economics (e.g. fishing), network access pricing, and so on.

In this paper, we discuss Guiasu's attempt to unify the Talmudic division problems into a single method. Guiasu (2011, pp. 65-66 and p. 78) states:

Three ancient problems, whose intriguing solutions were given without any justification back then, generated many studies with very different interpretations, debates, and controversy. Heuristic procedures and new concepts have been introduced, just to justify the numerical solutions given very long ago, but a uniform method for solving these three ancient problems was still missing.

... the main purpose of this paper, and of so many other papers about this topic, to find a rationale for the ancient solutions.

\footnotetext{
${ }^{1}$ Fon argues that the "Pari Passu" clause can be interpreted in terms of Talmudic division.
} 
The principle of division methods is the following. Consider two claimants denoted 1 and 2. Denote $E$ the total estate to be distributed and $x_{1}$ and $x_{2}$ the two payoffs. They are such that the sum of the payoffs does not exceed the value of the estate: $x_{1}+x_{2} \leq E ; d_{1}$ and $d_{2}$, with $d_{1} \leq d_{2}$, are the amounts claimed by the individuals with ; $x_{i} \leq d_{i}$ for any claimant $i$ and $d_{1}+d_{2}>E$ (the commodity to be shared is scarce: this is a "bankruptcy" problem; Moulin (2003, p. 261) calls it "deficit-sharing" or "rationing"). ${ }^{2}$ The important idea is that claims are exogenous. For example, Moulin (2003, p. 139) cites the case of a duo of musicians who have to determine their respective contributions but who are not equally famous. The claims may be symmetric, or unequal, but they are quantified and well defined. This type of problem is known as a rationing or bankruptcy problem.

Aristotle argues in Book 5 (Rackham 1934) ${ }^{3}$ that distributive justice must be proportional: each claimant must receive award in proportion to his claim: $x_{1} / d_{1}=x_{2} / d_{2}$. This is the same with three or more claimants. Proportional division is the familiar division rule we generally use.

While proportional division is quite simple, not so Talmudic division, a historical Jewish method of division that has recently come to prominence although it is more than two thousand years old (O'Neill 1982; Aumann ${ }^{4}$ and Maschler 1985; Young 1987; Deverney 1992; Benoit 1997; Dagan et al 1997; Kaminski 2000; Herrero and Villar 2001; Moulin 2002, 2003; Thomson 2003; Balinski 2003, 2005; Hokari and Thomson 2003; Moreno-Ternero and Villar 2004; Dominguez and Thomson 2006; Bosmans and Lauwers 2011). ${ }^{5}$ The Babylonian Talmud (in the Nézikin sedarim, in the Metsi'a, and in the Kethuboth) considers the contested garment problem. Two people lay claim to a garment; ${ }^{6}$ one for the whole garment, the other for half of the garment. The Talmud also explores the case where there are more than two claimants in the form of the three wives problem with its three claimants, the solution to which looked mysterious for two thousand years but was solved by Aumann and Maschler's (1985) coalitional procedure.

The Shapley value (Shapley 1953), which is a tool developed by the branch of economics (and applied mathematics) known as game theory, can be used to define a certain type of solution to the problem of dividing an estate. The Shapley value is is the revenue the agents who belong to a coalition are able to generate by cooperating. This concept from game theory might seem difficult to understand. However, (i) it is common knowledge that the contested garment problem can be solved by using the Shapley value (see for example Moulin (2003, pp. 57-58); (ii) Aumann and Maschler (1985) and Guiasu (2011) ${ }^{7}$ proved that

\footnotetext{
${ }^{2}$ If $d_{1}+d_{2} \leq E$, there is no division problem at all: each claimant obviously receives what he claims, with what remains being shared equally.

${ }^{3}$ See comments in Kraut (2005) or Gauthier and Jolif (1958-9).

${ }^{4}$ Nobel prize (actually: The Sveriges Riksbank Prize in Economic Sciences in Memory of Alfred Nobel) in economics, for the year 2005.

${ }^{5}$ Following Dagan et al. (1997, p. 58), the method was also studied by Pineles (1861), unfortunately for me in a text in Hebrew, not translated.

${ }^{6}$ A large fabric, like a toga, which can be divided up.

${ }^{7}$ See also Guiasu (2010).
} 
the solution to the coalitional procedure can be derived from the Shapley value. For Guiasu, it is the Shapley value-more exactly, the usual Shapley value, i.e., of a cumulative game,- 8 which is a misguided theoretical development because Aumann and Maschler (1985) showed that the coalitional procedure corresponds to the nucleolus (Schmeidler 1969), another completely different concept of game theory. ${ }^{9}$ It is important to discuss Guiasu's approach because he purports to unify all Talmudic division methods by the Shapley value, as shown by this excerpt (Guiasu 2011, p. 78):

The objective of this paper is to show that the game theory logic based on the Shapley value may be consistently applied for solving, in a uniform way, all three ancient problems, namely the three wives problem, the contested garment problem, and the rights arbitration problem. ${ }^{10}$

Obviously, then, game theory cannot be left aside even if it is unprepossessing for many: the discussion will be rather technical but, as underlined by Moulin (2003, p. 139) "Indeed, no systematic discussion of the ... problem was possible until the tools of ... game theory became available fifty years or so ago". I will set out the main concepts as simply as possible here.

In a nutshell, this paper is an attempt to determine whether it is possible to unify sharing methods according to the Talmud by the Shapley value as Guiasu $(2010,2011)$ did. And in particular, can the three wives problem be inferred from an easy to understand process such as the "run-to-the-bank", which corresponds to the most usual Shapley value (that of a cumulative game). I will show that the answer is no. The three wives problem stems from a more complicated and less intuitive process, the nucleolus (i.e., the Shapley value of a dual game), even if I show it follows a series of highly intuitive orthogonal projections.

\section{Talmudic division: the historical problems}

\subsection{Truncation}

First, it is worth noting that, for any system of division, truncation is indispensable. Without it, a claimant making an infinite claim could obtain the entire estate.

\footnotetext{
${ }^{8}$ In a cumulative game, the maximum value attributed to a coalition is, more or less, the sum of the value attributed to its members. These concepts will be defined precisely later.

${ }^{9} \mathrm{On}$ the idea of nucleolus, see also Maschler, Peleg, and Shapley (1979) and Arin and Inarra (1998). The nucleolus can be used to find the solution that minimizes, step by step, the largest inequality.

10 Ibn Ezra's Rights Arbitration Problem is not studied in this paper. It is completely different from the three wives problem, even if it is a generalization of the contested garment procedure. See ibn Ezra (1146); Rabinovitch (1973); O'Neill (1982); Aumann (2010); de Mesnard (2015).
} 
Example 1. Assume that a first claimant demands 300 and a second one 600 , the estate being 600 . Proportional division allocates $600 \times 300 / 900=200$ and $600 \times 600 / 900=400$ to each claimant, respectively. However, if agent 2 claims more than the worth of the estate, say 6000 , he obtains $600 \times 6000 / 6300=571.4$ and agent 1 just 28.6; if agent 2 claims 60,000, he obtains $600 \times 60000 / 60300=$ 597 while agent 1 receives just 3 . And so on. In the limit, agent 2 receives 600 and agent 1 zero.

Definition 1 Truncation Moulin (2003, pp. 37- 38, 262). If any claimant claims more than the entire estate, that is, if there is an $i$ such that $d_{i}>E$, his claim is replaced by $E$, i.e.,

$$
\tilde{d}_{i}=\min \left(d_{i}, E\right) \text { for any } i
$$

Throughout the paper, we order the claims such that $d_{1} \leq d_{2} \leq \ldots \leq d_{n}$; thus, truncated claims are ordered such that $\tilde{d}_{1} \leq \tilde{d}_{2} \leq \ldots \leq \tilde{\tilde{d}}_{n}$ with $\tilde{d}_{n} \leq E$. We also assume that $x_{i} \leq d_{i}$ for any $i$ such that nobody can receive more than his claim. Notice that the problem is one of "rationing", that is, ${ }^{11}$

$$
E<\sum_{i=1}^{n} \tilde{d}_{i}
$$

\subsection{The contested garment}

Two people lay claim to a garment; one for the whole garment, the other for half of it. This is an excerpt from the Talmud (Baba Mezi'a 2a, Chapter I, Babylonian Talmud, Daiches and Slotki, 1935):

Two [persons appearing before a court] hold a garment. One of them says, "I found it", and the other says, "I found it"; one of them says, "it is all mine", and the other says, "it is all mine", then the one shall swear that his share in it is not less than half, and the other shall swear that his share in it is not less than half, and /the value of the garment] shall then be divided between them. If one says, "it is all mine", and the other says, "half of it is mine", he who says, "it is all mine" shall swear that his share in it is not less than three quarters, and he who says, "half of it is mine" shall swear that his share in it is not less than a quarter. The former then receives three quarters [of the value of the garment] and the latter receives one quarter. If two ride on an animal, or one rides and the other leads it, and one of them says, "it is all mine", and the other says, "it is all mine", then the one shall swear that his share in it is not less than half, and the other shall swear that his share in it is not less than half, and [the value of the animal] shall then be divided between

\footnotetext{
${ }^{11}$ The case $\sum_{i=1}^{n} \tilde{d}_{i} \leq E$ is trivial. Each claimant receives his claim and what remains is shared equally.
} 
them. If both admit [each other's claims] or if they have witnesses [to establish their claims] they receive their shares without an oath. ${ }^{12}$

The first claimant receives what is not claimed by the other, that is, half of the estate; then the remaining half is shared equally, that is, the first claimant receives in all $3 / 4$ and the second $1 / 4$.

Example 2. In Figure 1, derived from Balinski's figures 1 and $2(2003,2005)$ depicting the famous case of the contested garment, point $I^{\prime}$ of coordinates $E / 2$ and $5 E / 4$ exceeds the estate because $5 E / 4>E$. Therefore, the corresponding demand is truncated, which gives point $I$ of coordinates $E / 2$ and $E$. Then, each claimant receives what is not claimed by the other, that is, $E-\tilde{d}_{2}$ and $E-\tilde{d}_{1}$ respectively; whatever remains (that is, $\tilde{d}_{1}+\tilde{d}_{2}-E$ ) is shared equally between both individuals, which gives

$$
\left\{\begin{array}{l}
x_{1}^{C G}=\frac{1}{2}\left(E+\tilde{d}_{1}-\tilde{d}_{2}\right) \\
x_{2}^{C G}=\frac{1}{2}\left(E-\tilde{d}_{1}+\tilde{d}_{2}\right)
\end{array}\right.
$$

As $x_{1}^{C G}+x_{2}^{C G}=E$ the entire estate is distributed and $x_{i}^{C G} \geq 0$ for any $i$. See also Balinski $(2003,2005)$ for a synthetic and easy-to-read presentation. In Figure 1, the line $B C$ represents all the feasible allocations of the estate $E$ between the two individuals $(B(0, E)$ and $C(E, 0))$. Point $I(E / 2, E)$ shows what both agents claim. Point $T(E / 4,3 E / 4)$ is the allocation according to Talmudic division. By truncation, point $I^{\prime}$, for which individual 1's claim exceeds the estate is also projected on $T$; at point $I^{\prime \prime}$, claimant 2 takes all: this proves how truncating is important and necessary. $A(E / 3,2 E / 3)$ is the "Aristotle point".

\footnotetext{
${ }^{12}$ Here, an "oath" is a pledge upon God.
} 


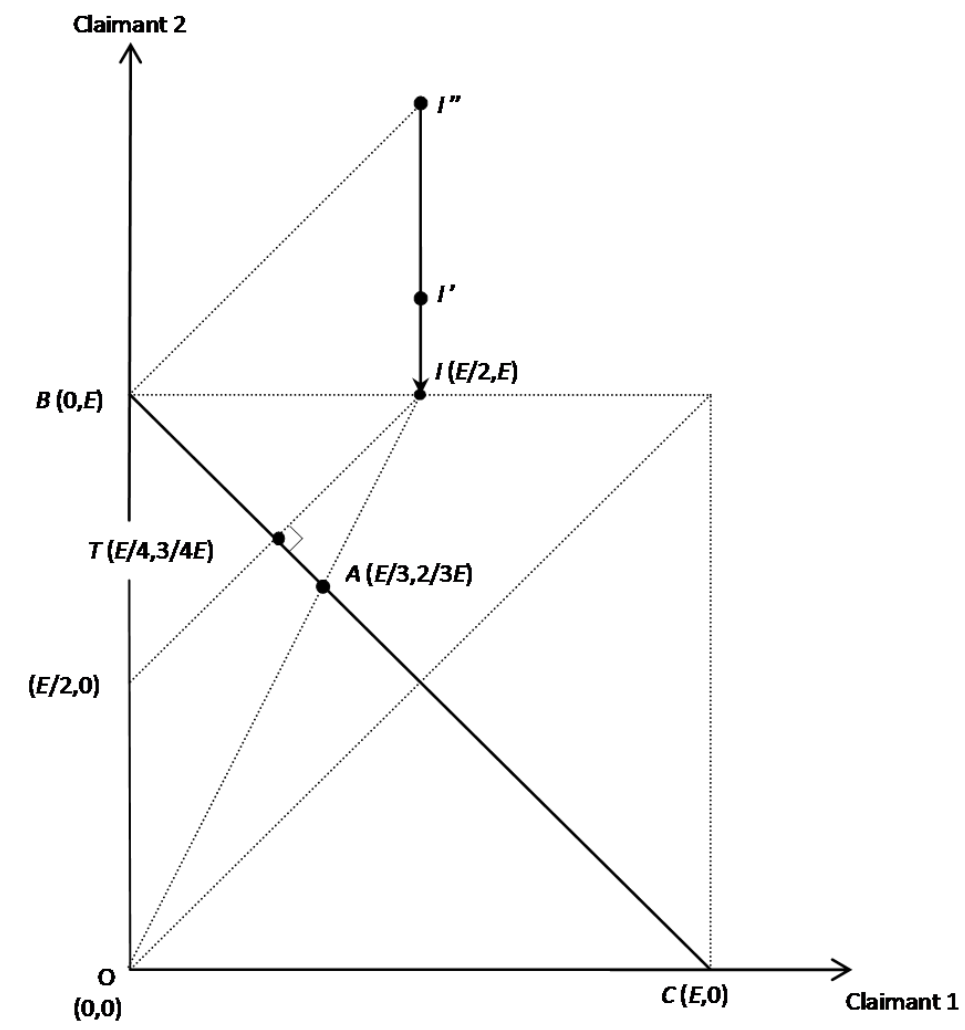

Figure 1: Contested garment (derived from Balinski (2003, 2005)).

Remark. Talmudic division may seem complicated and unclear; hence the many discussions of the Jewish masters about it and the many scholarly papers. However, and this has never been brought to the fore, in the non-trivial case where $d_{1}+d_{2} \geq E$, the method corresponds to the orthogonal projection, that is, to the minimization of Least Squares ${ }^{13}$ (or of the quadratic mean) between vectors $\tilde{d}$ and $x$ under the constraint $\sum_{i=1}^{2} x_{i}=E: \min _{x_{i}} \sum_{i=1}^{2}\left(x_{i}-\tilde{d}_{i}\right)^{2}$, s.t. $x_{1}+x_{2}=E$. The solution is $x_{i}=b+\tilde{d}_{i}$ for any $i=1,2$ where $b=$ $\left(E-\tilde{d}_{1}-\tilde{d}_{2}\right) / 2$, which is strictly equivalent to $(2) .{ }^{14}$ This criterion amounts to finding Gauss' orthogonal projection: the point of coordinates $\left(x_{1}, x_{2}\right)$ is the orthogonal projection of the point $\left(\tilde{d}_{1}, \tilde{d}_{2}\right)$ on the plane $x_{1}+x_{2}=E \cdot{ }^{15}$

It is possible to examine what happens when the estate varies: the claims $d_{1}$

\footnotetext{
${ }^{13}$ Least Squares are very popular in econometrics, but no stochastic hypotheses are made here.

${ }^{14}$ Young (1987, p. 410) indicates a completely different function, based on logarithms and exponentials.

${ }^{15} \mathrm{~A}$ distance and its square have the same minimum.
} 
and $d_{2}$ are given but $E$ is variable. With proportional division, $x_{1}$ and $x_{2}$ are always such that $x_{1} / d_{1}=x_{2} / d_{2}$. Discussing the contested garment, Aumann and Maschler (1985, p. 198) explain that:

When $E$ is small, it is divided equally. This continues until each claimant has received $d_{1} / 2$. Each additional dollar goes to the greater claimant, until each claimant has received all but $d_{1} / 2$ of her claim. Beyond that, each additional dollar is again divided equally. Note that the principle is monotonic, in the sense that for fixed claims $d_{1}$ and $d_{2}$, each of the two awards is a monotonic function of the estate E.

In other words, the unequal division begins when $E=d_{1}$ and ends when $E=d_{2}$. This is depicted in Figure 2, derived from Balinski's figures 1 and 2 (2003, 2005), where the coordinates of the points $A, B, C$, and $G$ are indicated in Table 1. When the estate is between 0 and $d_{1}$, Talmudic division shares equally between each claimant; they receive the same quantity up to $d_{1} / 2$ : Talmudic division is more egalitarian than proportional division. When the estate is between $d_{1}$ and $\left(d_{1}+d_{2}\right) / 2$, only claimant 2 increases his payoff with Talmudic division and catches up with 1 , up to $E=\left(d_{1}+d_{2}\right) / 2$ where proportional division and Talmudic division give the same result. Between $\left(d_{1}+d_{2}\right) / 2$ and $d_{2}$, it is again claimant 2 who receives all the additional payoff with Talmudic division, which increases the inequality beyond the proportional division. Between $d_{2}$ and $d_{1}+d_{2}$, with Talmudic division, 1 is again served, the same quantity being added equally to each payoff: this reduces inequality and for $E=d_{1}+d_{2}$, proportional division and Talmudic division yield the same result. In Figure 2, we see the constrained equal division. It is a method that apportions shares equally between both claimants, except that the claimants cannot receive more than they claim.

\begin{tabular}{|l|l|l|l|l|}
\hline $\begin{array}{l}\text { Distributions } \\
\text { and estate }\end{array}$ & $A$ & $B$ & $C$ & $G$ \\
\hline$x_{1}$ & $d_{1} / 2$ & $d_{1} / 2$ & $d_{1} / 2$ & $d_{1}$ \\
\hline$x_{2}$ & $d_{1} / 2$ & $d_{2} / 2$ & $d_{2}-d_{1} / 2$ & $d_{2}$ \\
\hline$E$ & $d_{1}$ & $\left(d_{1}+d_{2}\right) / 2$ & $d_{2}$ & $d_{1}+d_{2}$ \\
\hline
\end{tabular}

Table 1: Contested garment: coordinates of the four points in Figure 2. 


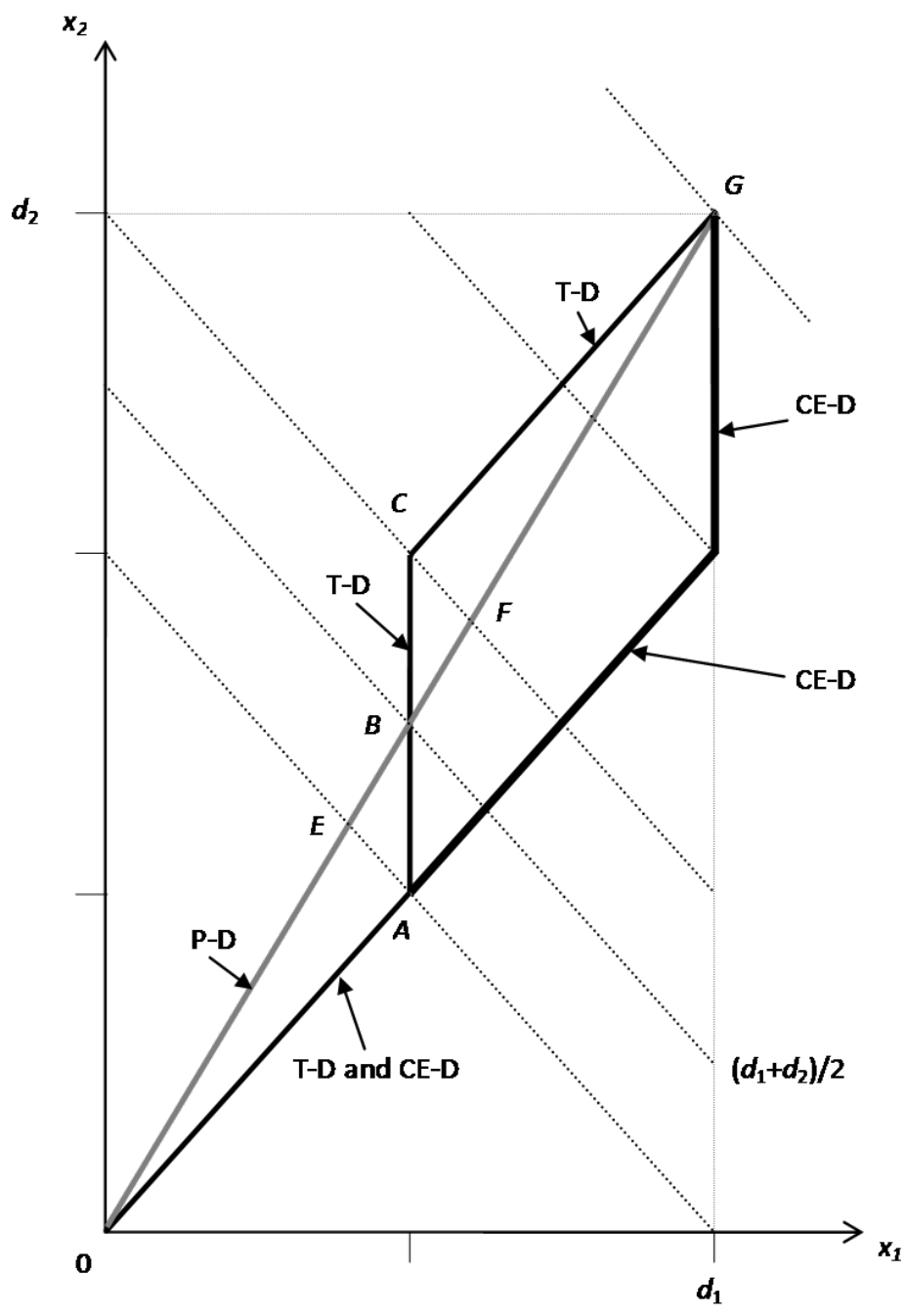

Figure 2: Contested garment when the estate varies (derived from Balinski (2003, 2005)). Notations. T-D: Talmudic division; P-D: proportional division; CE-D: constrained equal division. Dots: estate E.

\subsection{The three wives and Aumann \& Maschler' s coali- tional procedure}

The Talmud explores the three wives problem which was examined and extensively discussed by Aumann and Maschler (1985). The marriage contracts stipulate that upon the husband's death each wife is to receive 100, 200 and 300. The result is determined by the amount to be shared out. This is an excerpt 
from the Babylonian Talmud (Kethuboth, Folio 93a (Daiches and Slotki, 1935)):

If a man who was married to three wives died, and the kethubah of one was a maneh [a hundred zuz], of the other two hundred zuz, and of the third three hundred zuz and the estate [was worth] only one maneh [the sum] is divided equally. If the estate [was worth] two hundred zuz [the claimant] of the maneh receives fifty zuz [and the claimants respectively] of the two hundred and the three hundred zuz [receive each] three gold denarii. If the estate [was worth] three hundred zuz, [the claimant] of the maneh receives fifty zuz and [the claimant] of the two hundred zuz [receives] a maneh while [the claimant] of the three hundred zuz [receives] six gold denarii [one hundred and fifty zuz]. Similarly, if three persons contributed to a joint fund and they had made a loss or a profit they share in the same manner.

The outcome is depicted in Table 2 .

\begin{tabular}{|l|l|l|l|}
\hline \multirow{2}{*}{ Estate } & \multicolumn{4}{|l|}{ Claimants } \\
\cline { 2 - 4 } & 1 & 2 & 3 \\
\hline 0 & 0 & 0 & 0 \\
\hline 100 & $33 \frac{1}{3}$ & $33 \frac{1}{3}$ & $33 \frac{1}{3}$ \\
\hline 200 & 50 & 75 & 75 \\
\hline 300 & 50 & 100 & 150 \\
\hline 400 & 50 & 125 & 225 \\
\hline 500 & $66 \frac{2}{3}$ & $166 \frac{2}{3}$ & $266 \frac{2}{3}$ \\
\hline 600 & 100 & 200 & 300 \\
\hline
\end{tabular}

Table 2: The historical Talmudic three wives problem: the classic solution (with the supplementary lines for an estate of 400, 500 and 600).

Aumann and Maschler (1985) perform explicit Talmudic division for more than two claimants. They consider a series of contested garment procedures, but beginning with the claimant with the smallest claim. The claims are ordered in increasing order. The first claimant stands alone while the others form a coalition. The division is made between the two groups following the contested garment procedure; we see it is an orthogonal projection. Then the second claimant forms a coalition alone while the third up to the $n^{\text {th }}$ claimants form a second coalition, the division being made between the two groups as before; and so on. Hence the name coalitional procedure. In the classic problem of Table 2 , wives 2 and 3 form a coalition and wife 1 remains alone, then wives 2 and 3 share the remainder equally between themselves.

However, as the coalitional procedure consists of a succession of orthogonal projections, claimant $i+1$ may receive less than claimant $i$. In this case, the procedure is stopped and the remaining estate is shared equally between all remaining claimants. In the classic problem of Table 2 , this is the case if, for 
example, the estate is equal to 100 (the process is stopped at the first step because the orderly step-by-step process would give 50 to claimant 1 and only 50 to the other two, that is, $(50,25,25)$, which is not order preserving for the awards). This is also the case when the estate is equal to 500: the process is also stopped at the first step (the orderly step-by-step process would lead to a loss of 50 for the first claimant and of 50 for the other two together, that is, an allocation of $(50,175,275))$. It should be noted that the awards between $E=0$ and $E=300$ are symmetric to the losses between $E=600$ and $E=300$. Thomson (2003, p. 256) showed that the coalitional procedure can be presented in a different way. ${ }^{16}$

It worth noting that the outcome of the coalitional procedure depends on the order chosen for forming the coalitions: the results are completely different if some other order is chosen (de Mesnard 2008).

Example 3. Table 2 gives the classic solution of the three wives problem in the three columns on the left. The central three columns indicate the result when the coalitions are formed in reverse order. The three columns on the right show the solution when the coalitions violate the order of claims.

\begin{tabular}{|c|c|c|c|c|c|c|c|c|c|}
\hline \multirow[b]{3}{*}{ Estate } & \multicolumn{3}{|c|}{$\begin{array}{l}\text { Coalitions }\{1\}, \text { vs. } \\
\{2,3\}\end{array}$} & \multirow{2}{*}{\multicolumn{3}{|c|}{$\begin{array}{l}\text { Coalitions }\{1,2\} \text { vs. } \\
\{3\}\end{array}$}} & \multirow{2}{*}{\multicolumn{3}{|c|}{$\begin{array}{l}\text { Coalitions }\{1,3\} \text { vs. } \\
\{2\} \\
\text { Claimants }\end{array}$}} \\
\hline & \multicolumn{3}{|c|}{ Claimants } & & & Claimants & & & \\
\hline & 1 & 2 & 3 & 1 & 2 & 3 & 1 & 2 & 3 \\
\hline$\overline{0}$ & $\overline{0}$ & $\overline{0}$ & $\overline{0}$ & $\overline{0} 0$ & $\overline{0}$ & $\overline{0}$ & $\overline{0}$ & $\overline{0}$ & $\overline{0}$ \\
\hline 100 & $33 \frac{1}{3}$ & $33 \frac{1}{3}$ & $33 \frac{1}{3}$ & 25 & 25 & 50 & $33 \frac{1}{3}$ & $33 \frac{1}{3}$ & $33 \frac{1}{3}$ \\
\hline 150 & 50 & 50 & 50 & 37.5 & 37.5 & 75 & 50 & 50 & 50 \\
\hline 200 & 50 & 75 & 75 & 50 & 50 & 100 & 50 & $66 \frac{2}{3}$ & $83 \frac{1}{3}$ \\
\hline 300 & 50 & 100 & 150 & 50 & 100 & 150 & 50 & 100 & 150 \\
\hline 400 & 50 & 125 & 225 & 50 & 150 & 200 & 50 & 133 & $216 \frac{2}{3}$ \\
\hline 500 & $66 \frac{2}{3}$ & $166 \frac{2}{3}$ & $266 \frac{2}{3}$ & 75 & 175 & 250 & $66 \frac{2}{3}$ & 166 & 266 \\
\hline 600 & 100 & 200 & 300 & 100 & 200 & 300 & 100 & 200 & 300 \\
\hline Claims & 100 & 200 & 300 & 100 & 200 & 300 & 100 & 200 & 300 \\
\hline
\end{tabular}

Table 3: The three wives problem with the three possible coalitions. The case of coalitions $\{1\}$ vs. $\{2,3\}$ corresponds to the coalitional procedure.

However, we focus here on the order corresponding to the historic three wives problem and the coalitional procedure.

\footnotetext{
${ }^{16}$ See also Bosmans and Lauwers (2011).
} 


\section{Coalitional procedure and Shapley value of a cumulative game}

The contested garment and the three wives problem can be solved by the Shapley value (Aumann 2010; Guiasu 2011) which is now presented (Shapley 1953; Dubey 1975).

\subsection{Definitions}

The Shapley value can be interpreted in simple terms of the "run-to-the-bank" (Young 1995, pp.69-71; Moulin 2003, pp. 57-58). The claimants arrive randomly in the race to the bank; the first to arrive takes his full claim (which may be equal to the entire estate if what is available is equal to or less than his claim). Whoever arrives second does the same (he may receive zero if nothing is left), and so on. Assuming the order of arrival is random, all orders are equally probable: each claimant finally receives the expectation ${ }^{17}$ of all cases, which corresponds to the Shapley value. The run-to-the-bank is particularly well adapted to a problem of division, and computing the Shapley value by the run-to-the-bank is faster here. Remember also that truncation is applied to the data before any division. Table 3 gives an example computed by the "run-tothe-bank" for the case $E=200$ (remember that "run-to-the-bank" and Shapley value are equivalent), which is one of the cases where the results of the Shapley value differ from the Talmudic result.

\begin{tabular}{|l|l|l|l|}
\hline Order & $\begin{array}{r}\text { Claimant } 1 \\
(\text { claim }: 100)\end{array}$ & $\begin{array}{c}\text { Claimant2 } \\
(\text { claim }: 200)\end{array}$ & $\begin{array}{r}\text { Claimant3 } \\
(\text { claim }: 200)\end{array}$ \\
\hline 123 & 100 & 100 & 0 \\
\hline 132 & 100 & 0 & 100 \\
\hline 213 & 0 & 200 & 0 \\
\hline 231 & 0 & 200 & 0 \\
\hline 312 & 0 & 0 & 200 \\
\hline 321 & 0 & 0 & 200 \\
\hline Expectancy & $33 \frac{1}{3}$ & $83 \frac{1}{3}$ & $83 \frac{1}{3}$ \\
\hline
\end{tabular}

Table 4: The Talmudic three wives problem: $E=200$ computed by the "runto-the-bank"

However, this way of finding the solution is a particular case of Shapley value, even if it is the more usual, as we will see. This is why it is better to present the Shapley value in more general terms. $N$ is the set of all agents with $|N|=n . \quad S$ is a subset or coalition of $N$. Each subset is called a coalition. There are $2^{n}$ different possible coalitions of $N$ including the empty coalition (i.e. , $2^{N-1}$ non empty coalitions) or the coalitions that have only one element. The characteristic function is a simple mean to characterize a given coalition.

\footnotetext{
${ }^{17}$ In practice, we compute the mean.
} 
Definition 2. Characteristic value. The quantity $v(S)$ is the characteristic value that gives the maximum value of a coalition; it is a function

$$
2^{N} \rightarrow \mathrm{R} ; S \mapsto v(S)
$$

with $v(\phi)=0$ by definition (dummy axiom).

We are only interested in the maximum value this coalition may earn.

Example 4. If a coalition of two "gamers" earns 500 at the maximum, then we say that the characteristic value of the coalition is 500: $v(\{1,2\})=500$.

Any game is described by indicating the values of the characteristic function for any possible coalitions. The characteristic function can take several forms, depending on the type of game considered: cumulative, dual, etc. The property of superadditivity states that if a coalition $S_{T}$ is formed by the union of two coalitions $S_{1}$ and $S_{2}$, then the characteristic value of $S_{T}$ cannot be lower than the sum of the characteristic values of $S_{1}$ and $S_{2}: v\left(S_{T}\right) \geq v\left(S_{1}\right)+v\left(S_{2}\right)$.

Definition 3. Shapley value. The Shapley value $\varphi_{i \notin S}(v)$ of an agent $i$ (who does not belong to $S$ (i.e., $i \notin S$ )) is the sum of the marginal gains each individual brings upon joining all coalitions $S$ that can be formed among the set $N$ of all agents, that is,

$$
\varphi_{i \notin S}(v):=\sum_{S \subset N}[v(S \bigcup\{i\})-v(S)] p_{n}(S)
$$

where the quantities ${ }^{18}$

$$
p_{n}(S) \equiv \frac{|S| !(n-|S|-1) !}{n !}
$$

are the weights, that is, a count of the number of possibilities. ${ }^{19}$ The Shapley value is efficient, symmetric and additive. Moreover, those who claim nothing receive nothing.

We also define the nucleolus.

Definition 4. Nucleolus. Consider the members $i$ of a coalition $S: i \in S$; the payoffs of each member: $x_{i}$; the set of these payoffs is denoted $\mathrm{x}$. The surplus of a coalition is the difference between the characteristic value and the sum of the individual payoffs this coalition receives, that is,

$$
e(\mathbf{x}, S)=v(S)-\sum_{i \in S} x_{i}
$$

It is assumed that the coalition $S$ served first is the one with the largest surplus $e(\mathbf{x}, S)$ because "the one who yells loudest gets served first" (Ferguson

\footnotetext{
${ }^{18} S \bigcup\{i\}$ denotes the union of coalition $S$ and agent $i$.

${ }^{19}|S|$ denotes the number of members of coalition $S$, and $x$ ! the factorial of $x$, that is, the product $x \times(x-1) \times(x-2) \times \ldots \times 1 . n$ ! is the total number of possible coalitions. $|S| !((n-|S|-1) !)$ counts the number of coalitions that $i$ may join and $p_{n}(S)$ is the ratio between both quantities, that is, a relative count.
} 
2005, p. IV-22). Then, the set of payoffs $\mathbf{x}$ is adjusted so that the surplus becomes smaller but this increases the payoffs of the agents who are not in the coalition, and so on. The process stops when it becomes impossible to modify the payoffs: the set of payoffs that ensues is the nucleolus. The nucleolus is always unique (Driessen 1988, section II.7).

Remark. Saying that the nucleolus consists in minimizing, step by step, the largest inequality is equivalent to saying that the coalitional procedure consists of a series of orthogonal projections.

If there is a single definition of the Shapley value, the result depends on which game is considered. This affects the definition of the characteristic value. We examine this point now.

\subsection{Which game?}

For Aumann (2010) and later Guiasu (2011), the contested garment and the three wives problem can be solved by the Shapley value. This is perfectly true but everything depends on which definition of the characteristic function we consider, that is, which type of game we consider.

Aumann (2010) considers the dual characteristic value for the coalitional procedure.

Definition 5. Dual game. The following characteristic function is used:

$$
v(S):=\max \left(0, E-\sum_{i \in N \backslash S} v(\{i\})\right)
$$

Remember that $v(\{i\})$ is the characteristic value of each claimant, given for any $i \in S .^{20}$ The coalitional procedure is efficient and leads to a solution which is the nucleolus (Aumann and Maschler 1985). Moreover, and this is important here, Aumann (2010) has shown that the nucleolus can be generated by the Shapley value by considering the dual game, that is, (3) and (5). Aumann takes $v(\{i\})=\min \left(d_{i}, E\right) \equiv \tilde{d}_{i}$ for any $i \in S$.

Guiasu has taken the usual Shapley value, that is, the Shapley value of a cumulative game for the coalitional procedure, as proved by this excerpt (Guiasu 2001, p. 78):

Before using this tool, however, it is essential to identify what kind of games are involved in each of these problems. The decision making is based on the same tool, namely the game theory logic based on the Shapley value, but the specific games involved are slightly different. The kind of claims of the players and the relationship between the given claims and the given resources available, on one hand, and the specific way of evaluating the value of each possible coalition, on

\footnotetext{
${ }^{20}$ The game corresponding to (5) is superadditive. Aumann $\left(2010\right.$, pp. 8-9): " $v_{2}$ is superadditive, because there it is indeed a matter of what each coalition can get in the worst case: $v_{2}(S)$ is what is left for $S$ after all other claims are satisfied".
} 
the other hand, determine the particular type of game which has to be solved in each of the three ancient problems mentioned.

Therefore, we are led to define a cumulative game.

Definition 6. Cumulative game. In a cumulative game, $v(S)$ is given by

$$
v(S):=\min \left(\sum_{i \in S} v(\{i\}), E\right)
$$

This characteristic value differs from (5): Aumann (2010) says they are dual.

\subsection{Guiasu's approach}

Guiasu (2011) proceeds as follows. Sorting the claimants such that $d_{1} \leq \cdots \leq$ $d_{m-1}<E \leq d_{m} \leq \cdots \leq d_{n}$, in computing the characteristic value of each claimant, he posits an axiom that attributes the surplus of estate $E-d_{m-1}$ equally to the higher claimants $i=m, \cdots, n$, that is,

$$
v(\{i\})=d_{m-1}+\frac{E-d_{m-1}}{n-m+1} \text { for } i=m, \cdots, n
$$

with $v(\{i\})=d_{i}$ for $i=1, \ldots, m-1$.

Remark. (7) implies that the characteristic value of the highest claimant is equal to the estate: $v(\{n\})=E$.

Then, for a three-claimant problem, similar to the three wives problem, Guiasu applies equations (6) and (7) by making the distinction between three games: ${ }^{21}$

1. $E \leq d_{1} \leq d_{2} \leq d_{3}$ (corresponding to the case $E=100$ of the three wives problem) with $m=1$ (and $d_{0} \equiv 0$ ). By applying (6) and (7), Guiasu finds the solution $\left(\frac{E}{3}, \frac{E}{3}, \frac{E}{3}\right)$.

2. $d_{1}<E \leq d_{2} \leq d_{3}$ (corresponding to the case $E=200$ and yielding $v(\{2\})=v(\{3\})=150$ in the three wives problem) with $m=2$. According to (6) and (7) Guiasu finds the solution $\left(\frac{E+d_{1}}{6}, \frac{5 E-d_{1}}{12}, \frac{5 E-d_{1}}{12}\right)$.

3. $d_{1} \leq d_{2}<E \leq d_{3}$ (corresponding to the case $E=300$ in the three wives problem) with $m=3$. He makes the distinction between two cases: (i) $d_{1}+d_{2}<E$ where he finds the solution $\left(\frac{d_{1}}{2}, \frac{d_{2}}{2}, E-\frac{d_{1}}{2}-\frac{d_{2}}{2}\right)$ according to (6) and (7); (ii) $d_{1}+d_{2} \geq E$ where he finds the solution $\left(\frac{1}{6}\left(E+2 d_{1}-d_{2}\right), \frac{1}{6}\left(E-d_{1}+2 d_{2}\right), \frac{1}{6}\left(4 E-d_{1}-d_{2}\right)\right) .^{22}$

\footnotetext{
${ }^{21}$ The reader may refer to Guiasu (2011, pp. 72-73) for the detail of derivation of Guiasu's results.

${ }^{22}$ All these results are in accordance with the historic three wives problem of Table 2.
} 


\subsection{Questioning Guiasu's approach}

I will now prove that Guiasu's (20011) idea, ), followed by Alparslan and Sariarslan (2012), asserts, can be challenged for the coalitional procedure. ${ }^{23}$ Obviously, for two claimants, the Shapley value of a cumulative game leads to the same solution as with the coalitional procedure. It is common knowledge that for a two-person game, all symmetric and efficient solutions necessarily coincide. Therefore, the contested garment problem can be solved by the Shapley value of a cumulative game. ${ }^{24}$ However, things are different with more claimants. In particular, the Shapley value of a cumulative game cannot yield the same result as the coalitional procedure.

Proposition 1. After truncation, the Shapley value of a cumulative game and the coalitional procedure do not give the same result when $n>2$.

Aumann and Maschler (1985) showed that the coalitional procedure corresponds to the nucleolus of the game. Even if the nucleolus is known to differ from that of the Shapley value of a cumulative game as defined by (3)-(6), we provide a direct proof by a counter-example for a three-player game, ${ }^{25}$ which corresponds to the historical three wives problem.

Proof. Table 5 shows the outcome for the historical three wives problem solved by the Shapley value of a cumulative game. The case $E=200$ differs from what is found in the historical three wives problem as depicted by Table 2 . Appendix 5.2 also gives the computation of the case $E=200$ by the Shapley value formulas. It is noticeably that Guiasu's choice of a cumulative game corresponds to the run-to-the-bank. Appendix 5.3 gives the formal proof of this counter-example.

\begin{tabular}{|l|l|l|l|}
\hline Estate & Claimant & Claimant & Claimant \\
1 & 2 & 3 \\
\hline 100 & $33 \frac{1}{3}$ & $33 \frac{1}{3}$ & $33 \frac{1}{3}$ \\
\hline 200 & $33 \frac{1}{3}$ & $83 \frac{1}{3}$ & $83 \frac{1}{3}$ \\
\hline 300 & 50 & 100 & 150 \\
\hline
\end{tabular}

Table 5: Three wives problem: solution by the Shapley value of a cumulative game

How might Guiasu find the Talmudic result anyway? There are four arguments.

\footnotetext{
${ }^{23}$ Alparslan and Sariarslan (2012), followers of Guiasu (2011), work on the Average Lexicographic value (or Alexia value). Nevertheless, the Average Lexicographic value is equivalent to the Shapley value for convex games (Tijs 2005) and bankruptcy problems are convex (Curiel et al. 1987).

${ }^{24}$ For the interested reader, a direct proof is given in Appendix 5.1.

${ }^{25}$ The counter-example is the most powerful way to falsify a theory, in the Popperian (1959, 1963) sense.
} 


\subsubsection{Truncation}

Guiasu (2011, p. 71-72) does not truncate the data for deriving the solution to the three wives problem by the Shapley value. However, truncation must be done as is clearly stated by Moulin (2003, pp. 37-38, 262) or Balinski (2005, p. 504). In Aumann and Maschler this is implicit (1985, pp. 202-203). As said above, a claimant could beat the others and obtain the entire estate by placing an infinite claim.

\subsubsection{Difficulty for two claimants}

Guiasu's axiom (7) violates what is done in the historical problems. In the simplest case of two claimants, Guiasu states that the solution obtained with the Shapley value is of the form

$$
\left(\frac{d_{1}}{2}, E-\frac{d_{1}}{2}\right)
$$

However, (8) is not (2) even if both solutions are the same for some particular cases such as $d_{1}=1 / 2$ and $d_{2}=1$.

\subsubsection{Difficulty for the largest claim}

If we consider solution (8), equation (7) implies that $v(\{1\})=d_{1}$ and $v(\{2\})=$ $E$, whatever the real value of $d_{2}$. In other words, Guiasu considers that $d_{2} \geq E$, even if the case $d_{2}<E$ might be perfectly possible in a two-claimant bankruptcy problem, so long as $d_{1}+d_{2} \geq E$. There is no reason the upper bound of the estate should be $d_{n}$ and conversely, there is no reason claimant $n$ should be obliged to claim the whole estate.

Example 5. Consider the following two-claimant problem: ${ }^{26}$ the set of demands is $d=\left(\frac{1}{2}, \frac{7}{8}\right)$ with $E=1$. One cannot see why the first claimant may claim half of the garment and the second claimant may not claim less than the whole garment. The solution deduced from $(2)$ is $\left(\frac{1}{4}+\frac{1}{16}, \frac{3}{4}+\frac{1}{16}\right)=\left(\frac{5}{16}, \frac{11}{16}\right)$. By Guiasu's approach, it is again $\left(\frac{1}{4}, \frac{3}{4}\right)$, and remains unchanged for any $d_{2}$ larger than $1 / 2$ (i.e., any $\left.d_{2} \in\right] \frac{1}{2}, \infty[$ ).

\subsubsection{Discontinuity}

What is more, there is a discontinuity when Guiasu's result (8) is used. Such a discontinuity is not observed in the contested garment solution (2) and violates the following common sense axiom of continuity of payoffs:

Axiom. Continuity of payoffs. If two claims are close, the corresponding payoffs must also be close. In more formal terms, if we consider the function

\footnotetext{
${ }^{26}$ This example is inspired from the contested garment problem where $d=\left(\frac{1}{2}, 1\right)$ with $E=1$ and the solution of which is $\left(\frac{1}{4}, \frac{3}{4}\right)$.
} 
$[0, E] \stackrel{x}{\rightarrow}[0, E]$ of real values, the function $x$ must be continuous in any $\tilde{d}_{i} \in$ $[0, E]:$

$$
\exists \eta>0, \exists \varepsilon>0, \forall \tilde{d}_{j},\left|\tilde{d}_{i}-\tilde{d}_{j}\right|<\eta \Rightarrow\left|x_{i}\left(\tilde{d}_{i}\right)-x_{j}\left(\tilde{d}_{j}\right)\right|<\varepsilon
$$

Example 6. In the contested garment problem, where $E=1$, Guiasu's solution is $\left(\frac{1}{2}, \frac{1}{2}\right)$ for $d=\left(\frac{1}{2}, \frac{1}{2}\right)$. However, it is completely different, that is, $\left(\frac{1}{4}, \frac{3}{4}\right)$, as soon as $d_{2}$ is more than $1 / 2$, i.e., for $d=\left(\frac{1}{2},>\frac{1}{2}\right)$.

This is why Guiasu is able to find the classical solution to the three wives problem by the Shapley value: Guiasu's axiom (7) is largely ad hoc in the context of a bankruptcy problem solved by the coalitional procedure.

\section{Conclusion}

We have examined a historical Talmudic problem, the three wives, which generalizes the contested garment problem. It seems extraordinary to many that the ancient Rabbis could have developed a method for which the solution is so sophisticated but Aumann and Maschler (1985) solved the three wives problem using the coalitional procedure, a step-by-step application of the historic contested garment procedure. In his attempt to unify all Talmudic division methods by the Shapley value, Guiasu (2011) explains the coalitional procedure in terms of the "run-to-the-bank", that is, by considering the most usual Shapley value (that of a cumulative game). This is a misguided theoretical development as the solution to the coalitional procedure is the nucleolus. Therefore, Guiasu's paper is paradoxical. This is why my contribution consists in analyzing how Guiasu has been able to find his result.

Although it is unfamiliar to many, it has been necessary to return to game theory because, since Aumann and Maschler's contribution, the problem is definitively game theoretic by nature, even if it was developed by Rabbis centuries ago. So, after recalling what the Talmudic sharing problem is, how Aumann and Maschler's coalitional procedure explains its solution (i.e., the nucle-

olus or the Shapley value of a dual game; from the moment that the order of coalitions is defined, the solution is unique), and how Guiasu solves it by the usual Shapley value (i.e., of a cumulative game), it is shown here that:

1. Guiasu has overlooked data truncation (claims that exceed the estate must be reduced to the available amount of the estate); yet, truncating is required in the context (without truncation, any applicant may obtain all the available estate by simply making an infinite claim).

2. Guiasu poses an axiom which attributes the surplus (obtained after sharing out the estate) to all applicants equally. We show that this is inconsistent with the contested garment problem.

3. By Guiasu's axiom, the estate cannot exceed the claim of the agent who demands the most, which is obviously false. 
4. Guiasu's approach creates a discontinuity in the distribution of the estate, which is not observed in the contested garment problem.

We conclude that Guiasu's attempt to explain the three wives problem in terms of a "run-to-the-bank", that is, by the usual Shapley value (i.e. of a cumulative game) is unsuccessful. The correct explanation is given in terms of Shapley value of the dual game, that is, of the nucleolus. This should not be considered as a technical discussion among game theory specialists: Guiasu distorts the three wives problem so as to explain it in terms of the Shapley value of a cumulative game (or in terms of "run-to-the-bank") at all costs, transforming it into a complicated method, while it is simply and naturally explained in terms of the Shapley value of a dual game. This needed to be established for there to be a successful and convincing approach to Talmudic division.

\section{Appendix}

\subsection{The contested garment}

The characteristic value for an individual claimant $i$, i.e., $v(\{i\})$, should be defined as $i$ ' s claim but truncation (1) is applied: $v(\{i\})=\min \left(\tilde{d}_{i}, E\right)=\tilde{d}_{i}$ for any $i$. Here, $\tilde{d}_{1}=\frac{1}{2}, \tilde{d}_{2}=1$ : truncation changes nothing. Thus, the characteristic function takes the following values: $v(\phi)=0, v(\{1\})=1 / 2$, $v(\{2\})=1, v(\{1,2\})=\min (v(\{1\})+v(\{2\}), E)=1$. By applying (4), the weights are $p_{2}(\phi)=p_{2}(\{1\})=p_{2}(\{2\})=1 / 2$, knowing that $|0|=0$ and $0 !=1$. Thus, applying (3) gives $x_{1}=1 / 4$ and $x_{2}=3 / 4$ which is the Talmudic result.

\subsection{The three wives problem}

For the case $E=200$, first, truncation (1) is applied: $\tilde{d}_{1}=100, \tilde{d}_{2}=200$ and $\tilde{d}_{3}=200$. Applying (6) gives:

$$
\begin{gathered}
v(\phi)=0, v(\{1\})=\min (100,200)=100, \\
v(\{2\})=v(\{3\})=\min (200,200)=200 \\
v(\{1,2\})=v(\{1,3\})=\min (100+200,200)=200 \\
v(\{2,3\})=\min (200+200,200)=200 \\
v(\{1,2,3\})=\min (100+200+200,200)=200
\end{gathered}
$$

From (4), the weights are: $p_{3}(\phi)=1 / 3, p_{3}(\{1\})=p_{3}(\{2\})=p_{3}(\{3\})=$ $1 / 6$ and $p_{3}(\{1,2\})=p_{3}(\{1,3\})=p_{3}(\{2,3\})=1 / 3$. 


\subsection{Proof of the counter-example}

From $(6)$ we have $v(\phi)=0, v(\{i\})=\min \left(\tilde{d}_{i}, E\right)=\tilde{d}_{i}$ for any $i, v(\{i, j\})=$ $\min \left(\tilde{d}_{i}+\tilde{d}_{j}, E\right)$ for any $i, j \neq i$, and $v(\{1,2,3\})=\min \left(\sum_{i=1}^{3} \tilde{d}_{i}, E\right)=E$. The weights are: $p_{3}(\phi)=1 / 3, p_{3}(\{i\})=1 / 6$ for any $i$ and $p_{3}(\{i, j\})=1 / 3$ for any $i, j \neq i$. From (3), this gives the following payoffs:

$x_{i}=\frac{1}{3}\left(E+\tilde{d}_{i}-\frac{1}{2}\left(\tilde{d}_{j}+\tilde{d}_{k}\right)+\frac{1}{2} \min \left(\tilde{d}_{i}+\tilde{d}_{j}, E\right)+\frac{1}{2} \min \left(\tilde{d}_{i}+\tilde{d}_{k}, E\right)-\min \left(\tilde{d}_{j}+\tilde{d}_{k}, E\right)\right)$

for any $i$, with $j \neq k \neq i$. When $\tilde{d}_{1}+\tilde{d}_{2}<E$, this is

$$
\left\{\begin{array}{c}
x_{1}=\frac{1}{3}\left(E+\frac{3}{2} \tilde{d}_{1}-\frac{1}{2} \tilde{d}_{3}+\frac{1}{2} \min \left(\tilde{d}_{1}+\tilde{d}_{3}, E\right)-\min \left(\tilde{d}_{2}+\tilde{d}_{3}, E\right)\right) \\
x_{2}=\frac{1}{3}\left(E+\frac{3}{2} \tilde{d}_{2}-\frac{1}{2} \tilde{d}_{3}+\frac{1}{2} \min \left(\tilde{d}_{2}+\tilde{d}_{3}, E\right)-\min \left(\tilde{d}_{1}+\tilde{d}_{3}, E\right)\right) \\
x_{3}=\frac{1}{3}\left(E+\tilde{d}_{3}-\frac{3}{2}\left(\tilde{d}_{1}+\tilde{d}_{2}\right)+\frac{1}{2} \min \left(\tilde{d}_{1}+\tilde{d}_{3}, E\right)+\frac{1}{2} \min \left(\tilde{d}_{2}+\tilde{d}_{3}, E\right)\right)
\end{array}\right.
$$

When $\tilde{d}_{1}+\tilde{d}_{2} \geq E$, this is $x_{i}=\left(E+\tilde{d}_{i}-\frac{1}{2}\left(\tilde{d}_{j}+\tilde{d}_{k}\right)\right) / 3$ for any $i$ with $j \neq k \neq i$. This differs from the coalitional procedure.

\section{References}

ALPARSLAN G. and SARIARSLAN A. (2012) "On the Bankruptcy Situations and the Alexia Value," Journal of Applied Mathematics, doi:10.1155/2012/813060.

ARIN J. and INARRA E. (1998) "A Characterization of the Nucleolus for Convex Games," Games and Economic Behavior, 23: 12-24.

AUMANN R.J., (2002) "Game theory in the Talmud," Research Bulletin Series on Jewish Law and Economics, June 2002.

AUMANN R.J. (2010) "Some non-superadditive games, and their Shapley values, in the Talmud," International Journal of game Theory, 39: 3-10.

AUMANN R.J. and MASCHLER. M. (1985) "Game theoretic analysis of a bankruptcy problem from the Talmud," Journal of Economic Theory, 36, 2: 195-213.

BALINSKI M. (2005) "What is just?" The American Mathematical Monthly, June-July: 502-511.

BALINSKI M. 2003. "Quelle équité ?, Pour la Science," 311: 82-87.

BENOIT J.-P. (1997) "The Nucleolus is Contested-Garment-Consistent: A Direct Proof," J. Econ. Theory, 77: 192-196. 
BOSMANS K. and LAUWERS L. (2011) "Lorenz comparisons of nine rules for the adjudication of conflicting claims," International Journal of game Theory, 40: 791-807.

CURIEL I.J., MASCHLER M., and TIJS S.H. (1987) "Bankruptcy games," Zeitschrift für Operations Research, 31, 5: A143-A159.

DAGAN N., R. SERRANO et O.VOLIJ (1997) "A Noncooperative view of consistent bankruptcy rules," Games and Economic Behavior, 18, 1: 55-72.

DAICHES S. and W. SLOTKI M. (1935) Kethuboth, translated into English with notes, glossary and indices, EPSTEIN I. Ed.

de MESNARD L. (2008) "On the Talmud Division: Equity and Robustness," LVIIe Congrès annuel de l'Association Française de Science Economique, Paris, France, 18-19 septembre 2008. Dowloadable at

http://papers.ssrn.com/sol3/papers.cfm?abstract_id=1316002.

de MESNARD L. (2015) "On Ibn Ezra's Procedure and Shapley Value,"

Dowloadable at

http://papers.ssrn.com/sol3/papers.cfm?abstract_id=2561490.

DEVERNEY F. (1992) Le Problème de Partage du Talmud, Mini-projet de majeure Informatique (cours de J.-J. Levy), École Polytechnique, avril 1992.

DOMINGUEZ D. and THOMSON W. (2006) "A new solution to the problem of adjudicating conflicting claims," Economic Theory, 28, 2: 283-307.

DRIESSEN, T. (1988) Cooperative Games, Solutions and Applications, Kluwer Academic Publishers.

DUBEY P. (1975) "On the Uniqueness of the Shapley Value," International Journal of Game Theory, 4, 3: 131-139.

FERGUSON T.S. (2005) Game Theory, Course, Mathematics Department, University of California at Los Angeles. Downloadable at:

http://www.math.ucla.edu/tom/Game_Theory/Contents.html.

FON V. (2012) Sovereign debt default problem: an interpretation of the boilerplate yet mysterious pari passu clause, downloadable at:

www.apeaweb.org/confer/osaka13/.../Fon_Vincy.pdf.

GAUTHIER, R.A. \& J.Y. JOLIF. (1958-9) Aristote: L'Ethique à Nicomaque. 3 vols. Louvain: Publications Universitaires de Louvain,.

GUIASU S. (2011) "Three ancient problems solved by using the game theory logic based on the Shapley value," Synthese, 181, Supplement 1: 65-79. 
GUIASU S. (2010) Revisiting the Ancient Problems of Bankruptcy, Contested Garment, and Rights Arbitration, downloadable at: www.iiis.org/CDs2010/CD2010IMC/.../ZA212SU.pdf.

HERRERO C. and A. VILLAR (2001) "The three musketeers: four classical solutions to bankruptcy problems," Mathematical Social Sciences, 42, 3:

307-328.

HOKARI T. and THOMSON W. (2003) "Claims problems and weighted generalizations of the Talmud rule," Economic Theory, 21, 2-3: 241-261.

Ibn EZRA A (1146) Sefar ha-Mispar (" The Book of the Number," in Hebrew), Verona (German trans: Silberberg M. (1895), Frankfurt am Main: Kauffmann).

KAMINSKI M.M. (2000) “'Hydraulic' rationing," Mathematical Social Sciences, 40: 131-155.

KRAUT R. (2005) "Aristotle's Ethics," The Stanford Encyclopedia of Philosophy (Summer 2005 Edition), Edward N. Zalta (ed.), URL = $<$ http://plato.stanford.edu/archives/sum2005/entries/aristotle-ethics/>.

LITTLECHILD S.C. and G. OWEN (1973) "A Simple Expression for the Shapley Value in a Special Case," Management Science, 20: 370-372.

MASCHLER, M., PELEG, B. and SHAPLEY, L.S. (1979), "Geometric properties of the kernel, nucleolus, and related solution concepts," Mathematics of Operations Research, 4,4: 303-338.

MOULIN H.J (2002) "Axiomatic cost and surplus sharing," in: Arrow K.J., Sen A.K. and Suzumura K. (Eds.) (2002) Handbook of Social Choice and Welfare, Volume 1, Elsevier.

MOULIN H.J. (2003) Fair Division and Collective Welfare, Cambridge: MIT Press.

MORENO-TERNERO J. D. and VILLAR A. (2004) "The Talmud rule and the securement of agents' awards," Mathematical Social Sciences, 47, 2: 245- 257.

O'NEILL B. (1982) " A problem of rights arbitration from the Talmud," Mathematical Social Sciences, 2, 4: 345-71.

PINELES H. M. (1861) Darkah Shel Torah. Vienna: Forster (in Hebrew).

POPPER, K. (1959) The Logic of Scientific Discovery, Basic Books, New York, NY.

POPPER, K. (1963) Conjectures and Refutations, Routledge, London. 
RABINOVITCH N.L. (1973) Probability and Statistical Inference in medieval Jewish Literature. Toronto: University of Toronto Press.

RACKHAM H. (1934) Aristotle: The Nicomachean Ethics. London, William Heinemann Ltd. Reprinted in 1982 by Cambridge, MA: Harvard University Press.

SCHMEIDLER D (1969) "The Nucleolus of a Characteristic Function Game," SIAM Journal on Applied Mathematics, 17, 6: 1163-1170.

SHAPLEY L.S. (1953). " A value for n-person games," in Kuhn H.W. and W. Tuchker (Eds), Contributions to the Theory of Games II: 307-317.

THOMSON W. (2003) "Axiomatic and game-theoretic analysis of bankruptcy and taxation problems: a survey," Mathematical Social Sciences, 45: 249-297.

TIJS S.H. (2005). The First Steps with Alexia, the Average Lexicographic Value, CentER Discussion Paper No. 2005-123, Tilburg University, The Netherlands.

YOUNG H. P. (1987) " On dividing an amount according to individual claims or liabilities," Mathematics of Operations Research, 12, 3: 398-414.

YOUNG H. P. (1995) Equity: In Theory and Practice, Princeton (N.J.):

Princeton University Press. 